\section{Percepção das condições de trabalho em uma tradicional comunidade agrícola em Boa Esperança, Nova Friburgo, Rio de Janeiro, Brasil}

\author{
Perception of work conditions in a traditional \\ farming community in Boa Esperança, \\ Nova Friburgo, Rio de Janeiro State, Brazil
}

Frederico Peres 1

Sérgio Roberto de Lucca ${ }^{2}$

Luciana Muller Dantas da Ponte 1

Karla Meneses Rodrigues 1

Brani Rozemberg ${ }^{3}$

\section{Introdução}

1 Escola Nacional de Saúde Pública, Fundação Oswaldo Cruz, Rio de Janeiro, Brasil. 2 Faculdade de Ciências Médicas, Universidade Estadual de Campinas, Campinas, Brasil.

3 Instituto de Pesquisa Clínica Evandro Chagas, Fundação Oswaldo Cruz, Rio de Janeiro, Brasil.

\section{Correspondência} F Peres

Escola Nacional de Saúde Pública, Fundação Oswaldo Cruz. Rua Leopoldo Bulhões 1480 Rio de Janeiro, $R J$ 21041-210, Brasil. fperes@fiocruz.br

\begin{abstract}
The impact of pesticide use on human and environmental health has received attention from the international scientific community for some time, especially in developing countries where such chemical agents are used extensively and indiscriminately. The present study adopts a methodological approach to risk perception analysis based on rapid surveys, including: participatory observation; semi-structured interviews with key informants; and evaluation of local work processes. Field data analysis revealed several issues related to the risk perception profile of the study population, including the development of defensive strategies toward work hazards, subjective responses to potentially hazardous situations, and the role of individual risk perception as a determinant of human exposure to pesticides.
\end{abstract}

Pesticides; Occupational Health; Rural Workers; Occupational Risk; Perception
Nos últimos anos, profundas transformações têm sido observadas no trabalho rural brasileiro, seja no que diz respeito à incorporação de novas tecnologias e processos produtivos no meio rural, ou seja pela crescente subordinação do homem do campo à economia de mercado. Em ambos os casos, este processo de transformação acabou por determinar uma série de agravos à saúde e à qualidade de vida do trabalhador rural 1 , bem como contribui para a atual fragmentação do tradicional processo de produção agrícola e das organizações comunitárias dos pequenos produtores rurais que, historicamente, se desenvolveram em torno dessa atividade 2 .

De acordo com Graziano-Silva et al. 3, a mercantilização, tanto das atividades agrícolas quanto das relações de trabalho no meio rural, acabou por determinar uma crescente dependência das famílias rurais ao capital associado ao mercado agrícola. Esta vinculação, que no período de 1960 a 1980 propiciou uma verdadeira revolução no processo produtivo rural, estimulada por processos de mecanização das lavouras pelas políticas governamentais compensatórias/de incentivos e pelo emprego extensivo de agentes químicos para o combate às pragas, acabou por determinar o declínio da pequena produção rural, tradicionalmente associada à ideologia campesina dos imigrantes europeus 4 . 
Com a estabilização monetária decorrente do Plano Real, em 1994, observa-se no campo um aumento da perda do poder aquisitivo do pequeno produtor rural, decorrente da política de barateamento dos alimentos no mercado de varejo e da vinculação da cotação dos insumos agrícolas ao dólar americano 5 . Este fato acabou por determinar um novo êxodo rural, semelhante àquele observado no início do século passado 6 .

Em função do declínio da pequena atividade rural, de cunho familiar, e do trabalho assalariado nas grandes lavouras, cada vez mais pessoas estão abandonando esta tradicional ocupação e migrando em direção às periferias dos grandes centros urbanos, em busca de condições melhores de emprego (objetivo este que, na maioria dos casos, não é alcançado). Esse fenômeno é evidenciado nos grupos etários mais jovens e, sobretudo, entre as mulheres de 15 a 19 anos que, por serem resguardadas do enfrentamento direto das atividades de trabalho mais perigosas - sobretudo a utilização de agentes químicos, acabam por aceitar empregos de qualidade questionável - sobretudo em casas de família - em áreas urbanas 7. De acordo com Ribeiro \& Vivan 6 (p. 441): “as condições oferecidas pela agricultura não são atrativas, pois os custos de produção, a inconstância climática e os avanços tecnológicos são vistos como bloqueios pelo produtor; o capital de giro não existe, pois o agricultor que está e principalmente, o que volta ao meio rural, não possui condições de iniciar um processo de produção, que necessita de investimentos; a assistência necessária, seja ela técnica ou administrativa não ocorre e, desta forma, causa uma situação de impotência ao setor; as políticas de subsídios ou de crédito não chegam ao alcance destes agricultores, fazendo com que não possam iniciar suas atividades de forma competitiva".

Cavalcanti \& Mota (http://136.142.158.105/ Lasa2001/CavalcantiJosefa.pdf), alertam para a “desagriculturação" dos espaços rurais - uma pluriatividade de base não-agrícola, principalmente serviços domésticos, ao turismo e/ou a outras indústrias - e seu papel na determinância do êxodo rural e da fragmentação da tradicional comunidade camponesa. Para as autoras: "é preocupante reconhecer que os novos espaços agrícolas estão se formando com pouca ou nenhuma base local; as áreas agrícolas são áreas de trabalho mais do que área para viver: proprietários e trabalhadores parecem encontrar suas bases cotidianas nas cidades distantes ou mais próximas do seu local de trabalho; a agricultura não oferece hoje um espaço para 'a morada da vida'. Esses centros urbanos que atraem trabalhadores colocam em xeque tanto o sentido de ruralidade, pelo caráter da agricultura hoje, que longe está de ser uma atividade primária".

Assim, o desenvolvimento tecnológico e a inserção desfavorável do homem do campo na economia de mercado levam a rupturas no tradicional modelo agrícola, bem como nas comunidades a este associadas 4 . O presente trabalho tem como objetivo avaliar a percepção das condições de trabalho em uma da tradicional comunidade de pequenos produtores agrícolas da região de Boa Esperança, Município de Nova Friburgo, Rio de Janeiro, Brasil.

\section{A atividade agrícola em Boa Esperança}

A localidade de Boa Esperança está localizada no quinto distrito (Lumiar) do Município de Nova Friburgo, região serrana do Estado do Rio de Janeiro. Situa-se em um vale de média altitude (600-1.200m), cercado por escarpas montanhosas formadas a partir do encontro das Serras dos Órgãos e do Mar, região caracterizada por cobertura vegetal densa de matas pluviais, onde predomina um padrão arbóreo de médio para alto porte. Devido a esta peculiaridade, a região apresenta clima ameno, com temperatura média anual de $18^{\circ} \mathrm{C}$ e precipitações médias de $2.000 \mathrm{~mm}$, aproximadamente 8 .

A região de Boa Esperança, assim como grande parte do Município de Nova Friburgo, foi colonizada por imigrantes suíços e germânicos. Assim, houve um predomínio de pequenas propriedades rurais e do uso de mão-deobra exclusivamente familiar no processo de produção agrícola da região, cuja implantação na região remonta à chegada dos primeiros colonos suíços em 1820.

Segundo relatos dos moradores, a atividade agrícola na região acompanhou o crescimento observado em todo o município que, já na década de 1960-1970, e em função do processo de mecanização e do uso intensivo de agentes químicos nas lavouras, despontava como principal pólo produtor de olerícolas do Estado do Rio de Janeiro. Tomate, pimentão e couve-flor foram, até a década de 1980-1990, as principais lavouras da região, o que, em virtude das características desses produtos, da subordinação à economia de mercado e da forte pressão exercida pela indústria e pelo comércio local, determinou o uso indiscriminado de diversos agrotóxicos, acarretando em sérios problemas de saúde para a população e na contaminação do ambiente regional.

Com a estabilização da moeda e o aumento dos preços dos insumos agrícolas, sobretudo 
dos agrotóxicos, observou-se na região um acentuado declínio da atividade agrícola e, concomitantemente, a tendência migratória em direção ao centro urbano de Nova Friburgo e à região metropolitana do Rio de Janeiro.

\section{Metodologia}

Estudos anteriores 1,2,4,7,9,10,11,12,13,14,15,16,17 realizados em áreas rurais, apontam para algumas questões que devem ser consideradas quando da elaboração de um projeto de pesquisa centrado em relatos de vida e experiências de populações rurais. Uma primeira questão está relacionada com a minimização de possíveis constrangimentos frente ao entrevistador, sobretudo aqueles relacionados com o uso de linguagem rebuscada e/ou técnica durante as entrevistas. Além deste, outro ponto importante é a não-utilização de perguntas invasivas, passíveis de causar constrangimentos entre os entrevistados. Tomou-se, ainda, o cuidado, quando da caracterização da realidade de vida e de trabalho do homem do campo, em não reforçar estereótipos comumente observados em estudos no meio rural.

A coleta de informações deu-se baseandose em entrevistas semi-estruturadas, realizadas com base em um roteiro definido, ao qual o entrevistador tinha a liberdade de incluir novas questões, para possíveis desdobramentos das respostas dos informantes. Esse roteiro contemplou questões relacionadas com a descrição do processo de trabalho regional, dificuldades e problemas relacionados ao trabalho, satisfação com o trabalho, regime de uso de agrotóxicos, problemas relacionados ao uso de agrotóxicos e expectativas em relação ao trabalho. A elaboração do roteiro básico de entrevistas também se deu em conformidade com os pressupostos metodológicos levantados anteriormente.

A entrada da equipe em Boa Esperança foi facilitada pelo conhecimento prévio da comunidade por parte de um dos autores, morador da região. Na seleção dos informantes-chave foram feitas as seguintes escolhas: (1) trabalhadores que há mais tempo trabalhavam na agricultura (seis trabalhadores); (2) trabalhadores cujas propriedades tivessem maior produtividade e diversidade de lavouras (dois trabalhadores); e (3) trabalhadores que abandonaram a prática agrícola (quatro trabalhadores). Utilizou-se ainda alguns critérios de ordem mais geral, como a idade (maiores de 14 anos), uso de agrotóxicos no processo de produção (atual ou antigo) e interesse em participar do projeto de pesquisa (o que facilitou o processo de rea- lização das entrevistas, fato este que não foi conseguido em outros projetos de pesquisa, onde o informante selecionado aleatoriamente se sentia na obrigação de responder àquelas perguntas que lhe eram feitas, em clima de constrangimento, dificultando, assim, o processo de interlocução entre entrevistador e informante).

A coleta de dados foi realizada, como parte da monografia de especialização de dois dos autores 18 , durante uma visita de um dia à região no mês de agosto de 2001, onde foi possível observar também aspectos mais gerais, relacionados com a organização dos núcleos familiares, características topográficas e da cobertura vegetal, e da localização das lavouras. Naquela ocasião, encontravam-se as lavouras em época de colheita do inhame, sendo que em alguns sítios podia-se observar o preparo da terra para as culturas de verão (o tomate, principalmente). Este fato possibilitou abordar a questão do uso de agrotóxicos em uma das épocas em que mais se utilizam esses agentes químicos na região (na "capina química" - uso de herbicidas - realizada para a colheita do inhame e para o preparo de terras em "descanso" para o cultivo das lavouras de verão).

Os resultados que serão apresentados a seguir baseiam-se na análise dessas entrevistas. Em função da duração do trabalho em campo, a amostra de entrevistados foi construída com base em critérios de seleção prévia, baseados nos pressupostos do estudo, qualificando este grupo como informantes-chave. Duas principais limitações foram observadas nesta etapa da pesquisa: a primeira diz respeito à idade dos respondentes que, pelos critérios de seleção, deveria ser superior aos 14 anos. Entretanto, em função dos demais pré-requisitos, não encontrou-se nenhum informante-chave com menos de 35 anos. Ademais, em função da abrangência das respostas dadas durante as entrevistas, destacamos, na seção seguinte, aqui um maior número de falas dos informantes mais idosos.

Em segundo lugar, em função dos critérios de seleção anteriormente mencionados, não foi possível levar em consideração a influência da escolaridade: quase todos os informanteschave possuíam, como grau de escolaridade, o antigo primeiro grau (ensino fundamental) incompleto (somente um tinha o primeiro grau completo).

\section{Resultados e discussão}

A partir da avaliação das transcrições das entrevistas, foi possível identificar diferentes categorias de análises, que foram aprofundadas 
por meio de consulta à bibliografia pertinente, e cujos principais resultados encontram-se aqui descritos e discutidos.

\section{A fragmentação da tradicional atividade agrícola da região}

A análise do processo de trabalho rural na região de Boa Esperança, Nova Friburgo, Rio de Janeiro, desvelou um ofício fundado na própria organização dos núcleos familiares, formados por descendentes de imigrantes europeus, sobretudo de origem suíça e germânica. $\mathrm{O}$ aprendizado é transmitido, através das gerações, pelos pais ou chefes de família que, ao perpetrarem este conhecimento, acabam por determinar a organização de sua família em torno da atividade agrícola, conforme a própria estrutura das sociedades camponesas européias.

Ao longo dos anos, a orientação do processo de produção passa da subsistência e da atividade mercantil (troca de produtos) para se tornar uma atividade econômica, orientada pela lógica do mercado, que trouxe novas exigências à agricultura da região: “os antigo [avós] memo usava era lavoura de café, um pouco de cada coisa: aipim, bananeira. Tinha ovo em casa, galinha caipira, porco... Eles não comprava nada, não. (...) Plantava quase que só pra comer. Então não usava quase veneno" (ex-agricultor, 32 anos).

"[Antes] você plantava, roçava, queimava, plantava um milho, depois capinava, colhia. Aipim a mesma coisa, feijão a mesma coisa. Agora hoje não, hoje tem muita variedade de lavoura, né? Hoje você, como eu tô te falando, onde você tem um sítio que você precisa só pra você, hoje dá pra três quatro famílias. Com a técnica de viração de terra, adubação, mais uma coisa, mais outra, num é? Está produzindo muito mais. Mais variedade de mercadorias que produzia naquela época. E, então é assim, mas existe a dificuldade do preço da mercadoria também..." (agricultor, 72 anos).

Tal fato determinou uma mudança radical na lógica do processo produtivo, que passou a ser orientado pelo mercado consumidor do Estado do Rio de Janeiro, facilitando a disseminação do uso de técnicas que viabilizavam o aumento da produtividade, principalmente aquelas escoradas no emprego intensivo de agentes químicos - em especial agrotóxicos.

Entretanto, nos últimos anos, e de acordo com relatos de produtores locais, a atividade agrícola tem declinado significativamente. Tal fato encontra explicação, principalmente, nos altos preços de insumos agrícolas que, juntamente com a forte variação do mercado de pro- dutos olerícolas, tornam-se determinantes da decadência da atividade agrícola:

“Às vez, tem ano que (...) colhe muito. Aí, num dá preço. É sempre assim, quando dá muito num tem preço, quando dá pouco aí o preço fica bom, mas não faz quase nada. É o contrário. É uma coisa assim, um contratempo que dá" (ex-agricultora, 35 anos).

"A produção do nosso lugar aqui ela está pelo... de três partes ela está mais ou menos numa... Porque os novos estão tudo saindo pro emprego, porque começou... a lavoura dando pouco dinheiro, pouco preço. Os novos que eu estou te falando estão indo pra emprego; os velhos está fracassando, e aí a lavoura vai fracassando também. Fracassou muito. Eu vou te dizer a verdade, uns dez... de uns cinco, seis anos pra cá, fracassou muito a lavoura do nosso lugar aqui. É por isso que as coisas vai do jeito que vai" (agricultora, 72 anos).

"O trabalho do agricultor, rapaz, ultimamente anda meio esquisito sobre... você sabe como é que acontece: o preço [do produto] anda muito ruim, muito lá embaixo. Os insumos que a gente gasta na lavoura, sempre dá uma altazinha. Todo ano ele dá uma altazinha" (agricultor, 72 anos).

De acordo com Rozemberg \& Manderson 19, a inserção marginal dos pequenos produtores rurais brasileiros na economia de mercado, subordinada à agricultura comercial e às grandes empresas, acaba por determinar uma radical mudança no processo de trabalho, que contempla o aumento na carga de trabalho como tentativa de aumento da produtividade: " $n a$ tentativa insuficiente de compensar a desvalorização de seus produtos, produzindo mais $e$ trabalhando mais, os produtores rurais acabam vendo o resultado de sua produção não como 'mais ou menos lucrativo' e sim como 'mais ou menos prejuízo"' 19 (p. 166).

Apesar destes fatores, para a maioria dos trabalhadores entrevistados a atividade agrícola, ainda que árdua, foi considerada "muito boa" e "prazerosa" pela relativa autonomia e contato com a natureza que esta proporciona.

Curiosamente, ao identificarem os problemas da agricultura atual, os trabalhadores entrevistados fizeram uma relação direta entre o declínio da produção e o emprego de agrotóxicos nas lavouras. Dessa forma - ao contrário do que se poderia pensar - pela ótica do agricultor, o implemento desses produtos nas lavouras da região não promoveu o desenvolvimento da produção, e sim o fracasso desta.

Assim, sempre que solicitados a apresentar um relato sobre o histórico de uso de agrotóxicos na região, os trabalhadores identificavam 
uma relação direta entre o surgimento de novas pragas em suas lavouras e o crescente aumento do uso desses agentes químicos, identificando a atual situação observada no campo como "caótica", ou "extremamente problemática": "eu usei naquela época esse tal de veneno que você está falando, era um veneno só pra qualquer tipo de inseto que era... tinha o nome de Radiotoc e aquele veneno hoje você nem vê falar mais nele, né? Você nem falar mais no Radiotoc. Hoje parece um problemazinho na lavoura... e tal veneno assim. Amanhã aparece outro insetozinho, já tem que ser outro veneno diferente pra aquele inseto, pra aquele... pra aquele funguzinho que ataca a lavoura" (agricultor, 72 anos).

"Mas a coisa tá piorando tanto, tanto, tanto, que chegou a um ponto em que tudo que é veneno. Eu no meu pensar, no que eu entendo, né, as doença da lavoura foram se agravando, muitas qualidade de coisa pior, e eles foram tentando criar remédio para acabar com isso" (ex-agricultora, 35 anos).

“Naquele tempo produzia muito, sem química. Cói [colhe] 10, 20 por um de... carga de... plantava assim uma carga de batata, vamos supor. $100 \mathrm{~kg}$. Cói às veis $300,400,500 \mathrm{~kg}$. Hoje em dia bota a química, cói 200 , cói às veis menos. $E$ quer dizer o que que aconteceu? Aconteceu que foi a praga que veio. A praga veio, a ciência veio também. E então vamos combater a praga com a ciência, né? Com a ciência, que é o veneno" (agricultor, 76 anos).

A ciência, sinônimo de modernidade e desenvolvimento, torna-se, sob o ponto de vista dos trabalhadores, determinante do declínio de uma tradicional ocupação. Quando perguntada sobre as razões desse declínio, uma agricultora aponta os agrotóxicos como responsáveis pelo enfraquecimento dos solos da região: "porque a terra ficou fraca, né, eu acho que é isso. Porque meu pai era dono de terra, meu pai sempre trabalhou na lavoura, e nunca usou esses remédio e colhia boa plantação, bom milho. Tudo que prantava, colhia bem" (agricultora, 72 anos).

O declínio da atividade agrícola em Boa Esperança acabou por determinar, a partir de meados da década de 1990-2000, um processo de procura por postos de trabalho no centro urbano do Município de Nova Friburgo: "Eles [filhos] largaram de trabalhar na roça porque na roça tá muito fraco. Num tá dando muito dinheiro. Dá muito pouquinho... Porque o lavrador é muito explorado. Ele colhe, tem o maior trabalho. Depois ele vende muito baratinho. Lá na cidade as coisa é tudo caro, né? Mas quando sai da lavoura sai baratinho, tudo barato. Os meus dois filho, um tá trabalhando em obra e outro tá trabalhando empregado lá em Friburgo. Porque a lavoura tava dando muito pouco" (agricultora, 72 anos).

A decisão de deixar a agricultura, ao contrário do que se poderia esperar, é aceita e até mesmo estimulada pela família. A agricultura deixa de ter uma conotação familiar, para se tornar pouco compensatória além de perigosa, principalmente quando se leva em conta os riscos oriundos do processo de trabalho, sobretudo o uso de agrotóxicos: "eu prefiro que se ele [filho] arrumar uma outra profissão será melhor pra ele. [Por quê?] Lavoura está muito difícil aqui, né? (...) Porque, se não usar veneno... Se for, por exemplo, fazer uma lavoura de tomate, pimentão, outra coisa, se não usar veneno num colhe bem" (agricultor, 42 anos).

"Eu até gostaria, sim [que eles não trabalhassem com a lavoura e com o veneno]. Se eles tivessem, assim, uma capacidade, pegar um serviço que não dependesse de uma coisa tão perigosa. Que é muito perigoso, e a gente, a gente observa que deixa coidado na gente quando estão trabalhando com máquina e veneno, com essas coisa. A gente fica com coidado. Quer dizer que se tivesse um outro ramo pra trabalhar a não ser com isso, a... a capacidade da gente era outra, era muito melhor pra gente. Não dependia desse coidado que a gente tá tendo. E todo coidado, como eu já falei, não é o bastante, é pouco. Que quando tem que fazer mal, faz mesmo" (agricultor, 76 anos).

O depoimento acima, ainda que revele algum nível de reconhecimento do risco dos agrotóxicos, deixa entrever uma postura mais ou menos generalizada na região, de considerar-se que "quando tem que fazer mal, faz mes$m o "$, ou seja, a da inevitabilidade de seu uso e da impossibilidade de minimizar seus possíveis agravos e seqüelas. A ausência de registros do problema nos serviços de saúde também contribui para reduzir as chances de prevenção da intoxicação aguda e crônica, que em muitos casos sequer é percebida com tal 11 .

\section{Percepção de riscos relacionada ao trabalho rural}

O uso de agrotóxicos na lavoura é, hoje, segundo os relatos dos entrevistados, o principal problema relacionado ao trabalho rural.

A maioria destes agricultores, mesmo os que utilizam estratégias defensivas para negar o risco, parece reconhecer o uso de agrotóxicos como causador de agravos à saúde. Os principais sinais/sintomas relatados são dor de cabeça, dor de barriga e tonteiras: "eu tive uma cri- 
se, umas dores aqui... Assim... é a dor na barriga, assim por dentro, parece que... O médico disse que podia ser agrotóxico" (ex-agricultor, 36 anos).

"Sentia muita dor de cabeça. Dói a cabeça, muito grande. A vida inteira foi tomar Novalgina. Alivia, torna a voltar a doer. Num tem nada que faça melhorar" (ex-agricultora, 35 anos).

Os trabalhadores que haviam abandonado a atividade agrícola por algum problema de saúde, decorrente da exposição a agrotóxicos, foram os mais detalhistas em relação aos problemas relacionados ao uso de agrotóxicos, embora todos os demais entrevistados também tenham relatado problemas relacionados ao uso desses agentes químicos: "eu senti assim tontura, estômago revirado... Dor de cabeça. Jogando remédio nas lavoura. Umas duas ou três vezes. Por causa do remédio. Do veneno. A química. A gente pulveriza aquela química, aquilo é brabo e conforme o vento bate, toca pelo lado da gente, antão a gente respira aquele perfume da química, aquele cheiro forte. Então aquilo faz mal a gente" (agricultor, 76 anos).

"Aquele cheiro vai dando enjôo, vai prejudicando o estômago. De repente dá aquela dor de cabeça, né?" (agricultor, 42 anos).

Dois entrevistados se referiram aos agrotóxicos como possíveis causadores de infertilidade masculina e de efeitos teratogênicos, fator preponderante quando decidiram abandonar a produção agrícola.

“O médico falou pra mim um dia que a pessoa que trabalha muito na roça, o marido, né, que depois é perigoso até pra mulher engravidar. Podia nascer uma criança doente. Nasce criança com probrema. Aí nisso eu falava como Carlos que a pessoa que luta muito com o veneno é perigoso ficar doente e pra arrumar filho" (ex-agricultora, 35 anos).

Completam que a deficiência pode se estender aos filhos que nascerem.

"Tem criança que nasce deficiente devido ao agrotóxico" (ex-agricultor, 36 anos).

“A que eu lutei mais com o veneno, nasceu mais fraquinha, com menos peso. Já a mais nova, a gente já tava saindo assim pra outros trabalho, que eu num tava tendo, nem acho que cheguei perto de lavoura de veneno, ela nasceu mais gordinha" (ex-agricultora, 35 anos).

Os trabalhadores entrevistados, ao serem indagados sobre outros problemas do trabalho rural, citaram majoritariamente os problemas de coluna e os acidentes com animais peçonhentos: "a gente sente às vez depois de sair do trabalho é dor nas cadeira. Porque é pesado. A gente fica abaixado assim também trabalhado, a posição dá muita dor nas cadeira" (agricultora, 72 anos).
"Picada de cobra, aranha, se cortar com alguma ferramenta lá sozinho, perder muito sangue, né, é perigoso" (agricultora, 35 anos).

Os informantes, quando perguntados se já haviam se sentido mal durante e/ou após o uso de agrotóxicos, responderam diferentemente. Três homens responderam afirmativamente, enquanto as mulheres negaram eventos de intoxicação, justificando que suas tarefas na lavoura eram "serviço leve", como capinar o mato, arrancar e limpar os frutos, fato que, novamente, reforça a importância de estudos que focalizem, especificamente, a percepção de riscos das mulheres, relacionada ao uso de agrotóxicos.

No entanto, todos tinham casos de intoxicação de pessoas conhecidas para contar, como vizinhos, meeiros e amigos. Tal resultado já havia sido encontrado em trabalho realizado na região de São Lourenço, Nova Friburgo, Rio de Janeiro, onde se constatou que os casos de intoxicação eram sempre relatados na terceira pessoa, levando indivíduos, que haviam sido apontados por outros como protagonistas de casos de intoxicação, a negarem tal fato, relatando episódios vivenciados por outros 11 . O conceito de ideologia defensiva de Dejours 20 é muito pertinente aqui.

Em uma primeira análise poderia se pensar que as mulheres não estão tão expostas aos agrotóxicos quantos os homens, já que, geralmente, o processo de pulverização é uma tarefa masculina. Entretanto, mesmo durante esse processo, as mulheres ajudam os seus maridos, puxando as mangueiras - no caso de pulverizadores mecânicos - ou abastecendo os pulverizadores "costais" (manuais). Pelo fato de o marido estar no comando do pulverizador, as mulheres não percebem os riscos a que estão expostas: "ele [marido] reconhece muito as coisa. Ele fala que tem muitas coisa pra homem. (...) Porque pega a máquina de sulfatar, cheia de veneno. É pesado. Tem mulher que faz isso tudo. Mas, ele, não. Ele reconhece. (...) Pelo esforço memo. Num é coisa pra mulher, não" (agricultora, 35 anos).

"Nunca mexi [com veneno], se eu cheiro o veneno porque ele às veiz mexe aqui, passa, $t i$ nha lavoura ali perto, passava, o cheiro vinha até aqui. Eu nunca lutei, às vez ele me levava lá pras roça. Pra mim, não [tinha problema] porque eu não tava junto diária, né? Era um servicinho mais fácil. Mas ele [o marido] já enfrentou muito serviço bravo" (agricultora, 72 anos).

Para as mulheres entrevistadas, apenas os maridos estão expostos ao risco relacionado com a pulverização de agrotóxicos na lavoura, seja pelo esforço físico que esta atividade re- 
quer, seja pelo fato de estarem no comando do processo (usando o pulverizador costal ou segurando o bico da mangueira do pulverizador mecânico). Tal fato pode ser considerado como um agravante da exposição aos agrotóxicos pelas mulheres pois, embora não percebam os riscos relacionados ao uso desses produtos, elas muitas vezes estão mais expostas que os homens, seja pelo fato de, no momento em que o marido está pulverizando (e, muitas vezes, usando algum tipo de equipamento de proteção) a mulher encontra-se sem qualquer equipamento de proteção individual, ou por ser sempre a responsável pela lavagem dos equipamentos e das roupas utilizadas pelo marido no processo de pulverização.

\section{Estratégias defensivas}

Assim como a análise da percepção de riscos de uma determinada população ou grupo populacional específico é de fundamental importância para a avaliação de riscos, baseando-se nas perspectivas das ciências humanas e sociais, 0 conhecimento das principais estratégias de defesa desenvolvidas por estes profissionais e o impacto destas construções sobre a saúde também se apresentam como peças-chave no processo de relação entre o homem e o risco.

A partir da análise das entrevistas, pudemos desvelar a presença, na região, de uma perspectiva dominante de minimização e relativização do risco no uso de agrotóxicos, elaboração esta reforçada por uma culpabilização do trabalhador freqüentemente observada em material informativo e eventos onde se dá a comunicação sobre esses produtos 12,16 e presente nas falas dos trabalhadores entrevistados: “ $e o$ senhor acha que todo mundo, qualquer pessoa, pode trabalhar com veneno?" (entrevistador). "Pode trabalhar depende se tiver prevenido (...) [se tiver cuidado] num tem problema, não, mas como eu estou lhe falando, tem pessoas que é meio lambaião, mas pega passar por cima de tudo e num liga, quando vê fica intoxicado" (agricultor, 72 anos).

Outro ponto observado com a análise das entrevistas foi o fato de os trabalhadores associarem a contaminação por agrotóxicos a características individuais (para estes existem pessoas "fracas" para os agrotóxicos, e pessoas que podem "lidar com o produto sem problema"): "por exemplo, eu sou consumidor de cachaça, bebo muita cachaça. Com pouco tempo eu estou com meu fígado estourado, já está com cirrose, já estou morrendo. Você consome cachaça rapaz, você bebe a vida toda, como eu conheço pessoas aí que (...) que está com oitenta e nove anos.
Ela tem o garrafão de cachaça dela em casa. Ela tem o fumo dela, porque num fica sem fumar, se acordar de noite - o genro dela falou que sente lá da cama o cheiro do fumo que ela está fumando - e é assim rapaz. Então, é comparação de uma coisa com a outra. O outro fuma, morre de fumo, de cigarro há pouco tempo. O outro fuma a vida inteira, num tem problema. Assim éo problema do veneno, rapaz, tem organismo que se dá com o problema do veneno, já tem outro que num dá. Aqui pelo menos, aqui eu tenho essa pesquisa com essas coisas assim" (agricultor, 72 anos).

“Ah, meu jovem, você já falou sobre isso, né? Já deu problema, mas o que eu te falei: dá pra mim, num dá pra você, rapaz" (agricultor, 76 anos).

Tal fato, preponderante nas falas da maioria dos homens entrevistados, aparece como uma importante estratégia defensiva, pois transfere a outras pessoas a possibilidade de intoxicar-se por agrotóxicos. Esta questão nos remete, novamente, à ideologia defensiva, conforme descrita por Dejours 20.

Dejours identifica dois tipos básicos de defesas desenvolvidas pelos trabalhadores frente às injúrias relativas à organização do trabalho. O primeiro está relacionado com as construções individuais, que se caracterizam como as estratégias de defesa desenvolvidas por cada indivíduo frente ao risco inerente a uma tecnologia ou atividade perigosa, sobretudo aquelas inerentes ao processo e à organização do trabalho. Tais estratégias são construídas em resposta ao sofrimento de cada indivíduo e, geralmente, têm suas bases na trajetória de vida pessoal. O segundo tipo está relacionado com as construções coletivas, que o autor denomina de ideologia defensiva. Para o autor, a ideologia defensiva tem por objetivo "mascarar, conter e ocultar uma ansiedade grave. É um mecanismo de defesa elaborado por um grupo social particular, onde deve-se procurar uma especificidade" 20 (p. 56). Tal estratégia de defesa não é construída em resposta a uma angústia ou sofrimento individual, e sim destinada a lutar contra perigos e riscos reais, identificados pelo coletivo. A ideologia defensiva acaba por substituir os mecanismos de defesa individuais, tornando-os impotentes. Uma prova disso é, segundo o autor, o fato de o trabalhador, quando isolado de seu grupo social, ficar "brutalmente desprovido de defesas face à realidade a que ele é confrontado" 21 (p. 56).

Segundo esse autor, as estratégias de defesa individuais somem quando os riscos estão associados à organização do trabalho e/ou quando são muito próprios de um determinado gru- 
po social. Neste caso, os trabalhadores rurais acabam por negar coletivamente o risco, ou a aceitar a idéia de que são culpados individualmente pelas decorrências do uso de agrotóxicos. Esta última tendência encontra suas raízes, em parte, no processo de comunicação relacionado a esses produtos 11 .

De um modo geral, para os entrevistados parece ser um fundamental obstáculo à satisfação o fato de a produção não ter um valor monetário previamente estipulado e justo, algo que aponta para o não-reconhecimento social do trabalho agrícola.

“O problema que tem é que a gente trabalha bastante e às vezes calha que a gente não vende bem, né? A gente às vezes vende por pouco dinheiro, e aí a gente fica meio que entristece. Diz: 'Ah, trabalhei tanto e fiz tão pouco'. Isso é o que mais dá. Mas se contenta com aquilo que o Senhor dá. Porque o Senhor dá mais do que a gente merece" (agricultor, 76 anos).

\section{Considerações finais}

Os resultados aqui apresentados apontaram uma série de questões relacionadas ao impacto da adoção de novas tecnologias, sobretudo aquelas baseadas no uso extensivo de agentes químicos no meio rural sobre o tradicional processo de produção agrícola da localidade de Boa Esperança, Nova Friburgo, Rio de Janeiro.

Desde a década de 1960-1970, quando os agricultores da região optaram pelo modelo de produção agrícola intensiva, profundas mudanças vêm sendo observadas nesta localidade, principalmente no que diz respeito à organização do trabalho e dos núcleos familiares. A lógica "tradicional" de produção agrícola possuía profundas raízes na ideologia das comunidades campesinas européias, de onde havia migrado a grande maioria dos núcleos familiares da região. Era, portanto, uma lógica natural para estes habitantes, onde a família inteira se inseria nas etapas do processo produtivo e o conhecimento era transmitido ao longo das gerações que, ao redor desta atividade, acabaram por povoar a região de Nova Friburgo, hoje um dos principais pólos de colonização suíça e germânica do estado.

Na medida em que se dava o implemento destas novas tecnologias e da mudança do processo de produção em grandes áreas, produtores como os de Boa Esperança que mantiveram a lógica de produção campesina em suas propriedades se viram inseridos em processo de competição desleal. Em um segundo momento, esses produtores se viram obrigados a lotear/ vender suas propriedades para veranistas, e em muitos casos, acabaram por trabalhar para estes, seja por meio do regime de meia (direito ao uso-fruto da terra em troca de percentuais de sua produção) ou pelo trabalho assalariado.

Concomitante a este processo, observa-se no centro urbano do município um aumento na demanda de serviços, estimulado pelo turismo e pela crescente atividade industrial-têxtil, abrindo uma série de postos de trabalho que, paulatinamente, passam a ser ocupados por jovens imigrantes das zonas rurais, que deixam as propriedades de suas famílias para habitarem as periferias da região metropolitana do município.

A partir da década de 1990-2000, observase em Boa Esperança um declínio da atividade agrícola, determinado pela alta dos insumos, congelamento de preços dos produtos da lavoura e pelo crescimento do pólo produtor da divisa dos municípios de Nova Friburgo e Teresópolis (Centenário, São Lourenço, Vargem Alta, Salinas etc.) que, pelas características topográficas da região (áreas mais planas que a localidade de Boa Esperança) e pela proximidade com o mercado do produtor (CEASA), passa a dominar a produção de olerícolas na região.

As implicações deste fenômeno para a comunidade de Boa Esperança vão desde a queda do poder aquisitivo local, até o loteamento de grande parte das propriedades da região, com crescimento das propriedades de veraneio, criação de subempregos para os agricultores (antes autônomos) e drásticas modificações das condições ambientais e sanitárias. 


\section{Resumo}

O presente estudo objetivou investigar a forma como o impacto do uso de agrotóxicos sobre a saúde humana e o ambiente é um problema que tem merecido atenção da comunidade científica em todo o mundo desde há muito tempo, sobretudo nos países em desenvolvimento onde, sem os devidos cuidados, esses compostos são amplamente utilizados. O presente estudo objetiva a aplicação de uma metodologia de diagnóstico rápido para a avaliação da percepção de riscos no trabalho rural - sobretudo aquela relacionada ao uso de produtos agrotóxicos - frente às especificidades deste processo de trabalho e às idiossincrasias socioculturais do homem do campo. Esta metodologia inclui:observações participantes; entrevistas semi-estruturadas com informantes-chave; e avaliação do processo de trabalho. A análise dos dados desvelou uma série de questões relacionadas com a percepção de riscos da população estudada, incluindo o desenvolvimento de estratégias de defesa frente aos perigos vivenciados no trabalho, as respostas subjetivas frente a situações de potencial dano à saúde e o papel da percepção individual e coletiva dos riscos na determinação da exposição aos agrotóxicos.

Praguicidas; Saúde Ocupacional; Trabalhadores Rurais; Riscos Ocupacionais; Percepção

\section{Colaboradores}

F. Peres e B. Rozemberg participaram da pesquisa de campo e da redação do artigo. S. R. Lucca participou da redação do artigo. L. M. D. Ponte e K. M. Rodrigues participaram do levantamento dos dados de campo (entrevistas, transcrição e análise das entrevistas).

\section{Referências}

1. Alessi NP, Navarro VL. Saúde e trabalho rural: o caso dos trabalhadores da cultura canavieira na região de Ribeirão Preto, São Paulo, Brasil. Cad Saúde Pública 1997; 13 Suppl 2:111-21.

2. Rozemberg B, Peres F. Reflexões sobre a educação relacionada aos agrotóxicos em comunidades rurais. In: Peres F, Moreira JC, organizadores. É veneno ou é remédio? Agrotóxicos, saúde e ambiente. Rio de Janeiro: Editora Fiocruz; 2003. p. 367-84.

3. Graziano-Silva J, Del Grossi M, Campanhola C. O que há de realmente novo no rural brasileiro? Cadernos de Ciência e Tecnologia 2002; 19:37-67.

4. Alves E, Lopes M, Contini E. O empobrecimento da agricultura brasileira. Revista de Política Agrícola 1999; 8:5-19.

5. Lopes MR. Política agrária, uma década de deterioração. Agroanalysis 1996; 1:18-20.

6. Ribeiro EM, Vivan AM. Algumas questões sobre o desenvolvimento e a administração rural. In: Anais do Congresso Brasileiro de Administração Rural; Lavras: Universidade Federal de Lavras; 1999. p. 432-43.

7. Nunes R. Agricultura familiar: custos de transação, forma organizacional e eficiência [Tese de Doutorado]. São Paulo: Faculdade de Economia e Administração, Universidade de São Paulo; 2000. 
8. Empresa de Assistência Técnica e Extensão Rural. Programa Estadual de Desenvolvimento de Microbacias Hidrográficas, Nova Friburgo, RJ. Nova Friburgo: Empresa de Assistência Técnica e Extensão Rural; 2001.

9. Rozemberg B. O consumo de calmantes e o problema de nervos entre lavradores. Rev Saúde Pública $1994 ; 28: 300-8$.

10. Rozemberg B. A (in)transparência da comunicação: crítica teórico-metodológica sobre a interação do saber e das práticas médicas e a experiência das populações de áreas rurais endêmicas de esquistossomose [Tese de Doutorado]. Rio de Janeiro: Escola Nacional de Saúde Pública; Fundação Oswaldo Cruz; 1995.

11. Peres F. É veneno ou é remédio? Os desafios da comunicação rural sobre agrotóxicos [Dissertação de Mestrado]. Rio de Janeiro: Escola Nacional de Saúde Pública, Fundação Oswaldo Cruz; 1999.

12. Castro JSM. Práticas de uso de agrotóxicos no município de Cachoeiras de Macacu: um estudo de saúde ambiental [Dissertação de Mestrado]. Niterói: Universidade Federal Fluminense; 1999.

13. Oliveira Silva JJ, Alves SR, Meyer A, Peres F, Sarcinelli PN, Mattos RCO, et al. Influência de fatores socioeconômicos na contaminação por agrotóxicos no Rio de Janeiro, Brasil. Rev Saúde Pública $2001 ; 35: 130-5$.

14. Navarro Z. Desenvolvimento rural no Brasil: os limites do passado e os caminhos do futuro. Estudos Avançados 2001; 15:27-33.
15. Peres F, Rozemberg B, Alves SR, Moreira JC, Oliveira Silva JJ. O processo de comunicação relacionado ao uso de agrotóxicos em uma região agrícola do Estado do Rio de Janeiro. Rev. Saúde Pública 2001; 35:564-70.

16. Levyguard YE. A interpretação dos profissionais de saúde acerca das queixas do nervoso no meio rural: uma aproximação ao problema das intoxicações por agrotóxicos [Dissertação de Mestrado]. Rio de Janeiro: Escola Nacional de Saúde Pública, Fundação Oswaldo Cruz; 2001.

17. Moreira JC, Jacob SC, Peres F, Lima JS, Meyer A Oliveira Silva JJ, et al. Avaliação integrada do impacto do uso de agrotóxicos sobre a saúde humana em uma comunidade agrícola de Nova Friburgo/RJ. Cienc Saúde Coletiva 2002; 7:299-311.

18. Ponte LMD, Rodrigues KM. A percepção de risco do uso de agrotóxicos na Região de Boa Esperança, Nova Friburgo/RJ [Monografia de Especialização]. Rio de Janeiro: Escola Nacional de Saúde Pública, Fundação Oswaldo Cruz; 2001.

19. Rozemberg B, Menderson L. "Nerves" and tranquilizer use in Rural Brazil. Int J Health Serv 1998; 26:165-81.

20. Dejours C. A loucura do trabalho. São Paulo: Cortez; 1992.

Recebido em 24/Nov/2003

Versão final reapresentada em 22/Mar/2004

Aprovado em 26/Abr/2004 